\title{
Bringing it all together: researcher dialogue to improve synthesis in regional climate adaptation in South-East Queensland, Australia
}

\author{
Bruce M. Taylor • Ryan R. J. McAllister
}

Received: 3 February 2013/Accepted: 12 July 2013/Published online: 9 August 2013

(c) The Author(s) 2013. This article is published with open access at Springerlink.com

\begin{abstract}
The effectiveness of climate adaptation policies in one sector can be compromised or aided by policies developed in another sector. When the focus of adaptation is a single geographical region, this potential for interaction between sectoral policies is heightened due to spatial, political and functional proximities. This paper analyses interactions within three suites of climate adaptation options developed for Australia's 'South-East Queensland' region relating to: (1) wetland migration, coastal infrastructure and planned retreat; (2) urban water security and energy demand; and (3) terrestrial biodiversity and agricultural viability. Using the concept of 'institutional interplay' to structure a process of dialogue amongst researchers, we identify a number of critical implementation requirements for successful regional-scale adaptation. There is a need for greater focus on neighbourhood or subregional scales of policy design and intervention, particularly for the coordination of adapted infrastructure and services to households. Policy-makers must also be more explicit in considering broader drivers of land-use change and economic adjustment likely to impact on proposed adaptations. In considering these issues, our paper also demonstrates a process for conducting cross-sectoral syntheses that can be employed in other regional-scale adaptation studies.
\end{abstract}

Keywords Regional planning · Multi-sector · Policy integration · Research synthesis - Institutions · Dialogue

B. M. Taylor $(\bowtie) \cdot$ R. R. J. McAllister

CSIRO Ecosystem Sciences, PO Box 2583,

Brisbane, QLD 4001, Australia

e-mail: bruce.taylor@csiro.au

\section{Introduction}

Researchers are increasingly engaged in multi-sectoral analyses to inform the development of integrated regional policies for climate adaptation (see for instance Holman et al. 2005; Kirshen et al. 2008; Reyer et al. 2012). Despite this, concurrent research into the design of suitable policy and planning responses is still in its infancy (Hunt and Watkiss 2011; Moffet et al. 2011). The challenges facing both policy design and multi-sectoral regional research include balancing multiple outcomes and working at several spatial and organisational scales. Further, these challenges must be tackled under conditions of institutional fragmentation, contested goals and values, and insufficient scientific knowledge (Hanger et al. 2013). Developing an integrated response is nearly always considered a desirable goal (i.e. normatively speaking); however, integration in these types of problem contexts is often impractical or highly problematic in political, social and institutional terms (Mitchell 1990; Lane et al. 2009; Derkzen et al. 2009; Biswas and Tortajada 2010).

Given the influential role of scientific knowledge in framing environmental policy and sustainable development debates (Ozawa 2005; Owens and Rayner 1999; Rydin 2003), there is a critical need for researchers to support integrative policy design by thinking more synthetically (Agrawal et al. 2012). Yet, researchers, along with government agencies or private organisations, often contribute unwittingly to fragmented outcomes because of their particular functional, jurisdictional and expertise-based orientations (Scholz and Stiftel 2005). Indeed, adaptation has previously been described as myopic and driven by sectoral considerations or policy goals (Low 2008; Leitch et al. 2010). This may contribute to otherwise avoidable maladaptations or missed synergies. At the most basic level, 
dialogue between sectors, and between those that research sectoral adaptation options with stakeholders, is 'critical in ensuring that adaptation in one sector does not have a negative effect on another' (Mather et al. 2011: 562). Researchers are a distinct expert group in the design and implementation of adaptation policies. When equipped with a broader understanding of the likely interactions between proposed adaptation options, researchers can mainstream more integrative thinking into their engagement with stakeholders. In this way, it is possible to preempt undesirable outcomes and also improve overall integration within complex environmental policy processes.

There are three important questions arising from the above. First, how might the potential for fragmentation within complex sector-based adaptation initiatives be reduced? Second, how can we approach this task in an analytically and conceptually robust way that leads researchers to a more integrative understanding of the problems, and the opportunities, at hand? Third, what are the implications of such an approach for improving the design of adaptation policies, within the existing limits of current research and policy-making practice?

This paper applies a synthetic, analytical perspective to suites of adaptation options developed within the sectoral research portfolios of a large, regional-scale climate adaptation project - the 'South-East Queensland Climate Adaptation Research Initiative' (SEQCARI). Our discursive synthesis approach is presented for three suites of adaptation options: (1) planned retreat, coastal defence and wetland migration; (2) energy efficiencies and urban water security; and (3) terrestrial biodiversity management in rural landscapes anticipating growing economic and climatic pressures. This approach provides an alternative to the economic rationalist and rational-comprehensive models that characterise the contemporary science-policy interface and are common in the climate adaptation literature (e.g. Hill and Olson 2013, and see Hajer and Wagenaar 2003; Fischer 2003; Rydin 2003 for in-depth discussion of the implications of these two policy-making strategies). More generally, this paper explores the value of adopting such an approach to the task of research synthesis in regional climate adaptation problem contexts.

\section{Concepts for synthesis: regional integration as institutional interplay}

The development of local and regional adaptations is often tied to economic returns within given sectors (e.g. Stewart and Wang 2011; Rambaldi et al. 2013). Such sectoralspecific responses are easily costed and rationalised within a given organisational mandate or budget (Gunningham and Rees 1997). However, economic efficiency should be seen as a necessary but not sufficient criterion for selecting preferred policy responses. This is because economic efficiency does not engage with the implications and contingent character of interaction between options; between the multiple entities responsible for implementation; and the existing rules and practices that govern the legitimacy of activities by those entities (van Buuren et al. 2013).

Contradictions between sectoral responses are interactions that reduce the efficacy, efficiency or appropriateness of adaptation responses in other sectors. Kirshen et al. (2008), in their examination of interdependencies between adaptation strategies in Metropolitan Boston, USA, compare major sectoral adaptation responses on a sector-bysector basis. They identify a number of sector-specific adaptation options that risk confounding regional mitigation efforts. However, they also identify numerous sectoral adaptation options that produce co-benefits in other sectors. Other terminologies have been used to describe the consequences of interactions between different adaptation options. Reyer et al. (2012) employ the terms 'synergies' and 'conflicts' to describe the interaction between the intended consequences of a measure and unintended positive or negative side effects. Reyer et al. (2012) consider interactions within sectors as well as between them, and on how the mix of social, economic and environmental outcomes might be affected. Whilst our study echoes the aspects of Reyer et al. (2012) framing, we adopt Kirshen et al. (2008) terminology of contradictions and co-benefits. This arguably simpler framing serves our particular purpose. That purpose includes leaving adequate analytical space to consider the underpinning institutional dynamics of the interactions, not only the consequences of interaction.

To explore institutional dynamics, we employ Young (2002) ideas of 'interplay' to probe interactions between types and levels of organisation, and the rules that influence their interaction. The concept of interplay recognises that institutions are not 'self contained arrangements [but] interact with other similar arrangements both vertically and horizontally' (2002:23). This paper defines institutions broadly as the normalised rules and practices that govern human action, which in the type of problem context discussed here can more specifically be considered as resource management or environmental regimes (Young et al. 1999).

Vertical institutional interplay occurs between different levels (or scales) of social organisation, such as the household, neighbourhood, locality, region or nation. Studies of policy integration in climate adaptation highlight the importance of interactions between institutions. Urwin and Jordan (2008) point to how national-level or regionallevel understandings of what ought to be done can differ significantly from local perspectives on what can 
practically be done 'on the ground'. Indeed, cross-scalar interactions contribute significantly to the institutional complexity associated with integrated regional policy initiatives (Morrison 2007).

Horizontal interplay occurs between institutions (or regimes or policies) at the same level of social organisation (Young et al. 1999; Young 2002). Urwin and Jordan (2008) report that much of the policy interplay literature to date has, for instance, focused on the interaction of policies and institutions at the global level citing as an example the international climate change convention and the Montreal protocol on ozone depletion.

Young (2002) also suggests that there are two distinct types of institutional interplay. Functional interdependencies are present when actions, within a complex system of economic, social and environmental components, are linked through biophysical-geophysical relationships. Interdependencies in the politics of institutional design and management occur when different sectoral interests intentionally forge links between issues and institutions in order to pursue individual or collective goals (Young 2002; Young et al. 1999; McAllister et al. 2013). Functional interdependencies often give rise to political ones, where the motives of sectoral interests may be cooperative or competitive in character.

In our study, we examine interplay between regional adaptation options emerging from individual sector-based programmes of research. We structure this examination first by exploring co-benefits and contradictions, and second using the concepts of vertical and horizontal institutional interplay. Being explicit about these different dimensions allows sectoral stakeholders, planners or researchers tasked with the job of facilitating more integrated approaches to be explicit about what they mean by integration and how this might differ from other actors' understanding or goals of integration. Further, there are implications of these competing sectoral perspectives for achieving more cohesive action at the regional level.

\section{Methodology: a discursive approach to research synthesis}

For this study, we structured discussions amongst 15 scientists from research organisations including three universities, and state and national government science agencies. These scientists, as participants in the SEQCARI, were engaged as experts in applied research on sectoral adaptation options in close cooperation with government, industry and community stakeholders in the SEQ region, and engaged in several regional policy and planning forums. The participation of these scientists in the synthesis process was an explicit, planned step of the broader
SEQCARI project. The scientists identify with diverse disciplinary backgrounds such as conservation biology, materials engineering, agronomy, urban and environmental planning, and constructivist social science. Surfacing and examining co-benefits, contradictions, and vertical and horizontal institutional interplay through discussion about adaptation options have both practical and reflexive benefits. Understanding these factors can moderate or delay financial costs likely to arise from myopic design and implementation of adaptations derived from a single sectoral perspective (Agrawal 2008). Debating these factors improves the likelihood that potential conflicts in the goals, design and implementation of adaptation policies can be identified and resolved. The insights gained from the structured, expert dialogues with researchers in this study provide an example of how to make progress towards these types of outcomes.

Seeing dialogue as a process of collective sense-making (Forester 1989) is central to our methodological approach. It recognises the institutional, political and highly contextualised character of policy and planning where competition between multiple truth claims, made by different actors or interests, determines acceptable action (Hajer and Wagenaar 2003; Fischer 2003; Rydin 2003; Bulkeley 2010; Lovell et al. 2009; McAllister et al. 2013). The same dynamics, we argue, also hold for the diverse disciplinary and epistemological perspectives on adaptation that arise in sectoral-oriented programmes of research. Following Forester (1989) approach, in this study, we requested information from, and posed questions to, participants in order to organise attention around specific themes. We made written records of discussions, drew on participants' own notes of the discussions, and undertook follow-up questioning. The method involved four steps conducted over several months.

Step 1: Identifying preliminary adaptation options from sectoral research

This initial stage involved encouraging researchers to document the preliminary adaptation options arising from their particular sectoral research programmes. ${ }^{1}$ To provide some consistency in reporting, we designed a standard template (see Tables 1, 2, 3) which asked researchers to explicitly describe the:

\footnotetext{
${ }^{1}$ This exercise yielded 130 preliminary adaptation options from research teams in: human settlements; infrastructure; water (sourced from outside of SEQCARI); energy; biodiversity and adaptive capacity. The SEQCARI project as a whole considered a far greater range of adaptation options including a specific suite of 'integrated' adaptation options (see, e.g. Serrao-Neumann et al. 2013).
} 


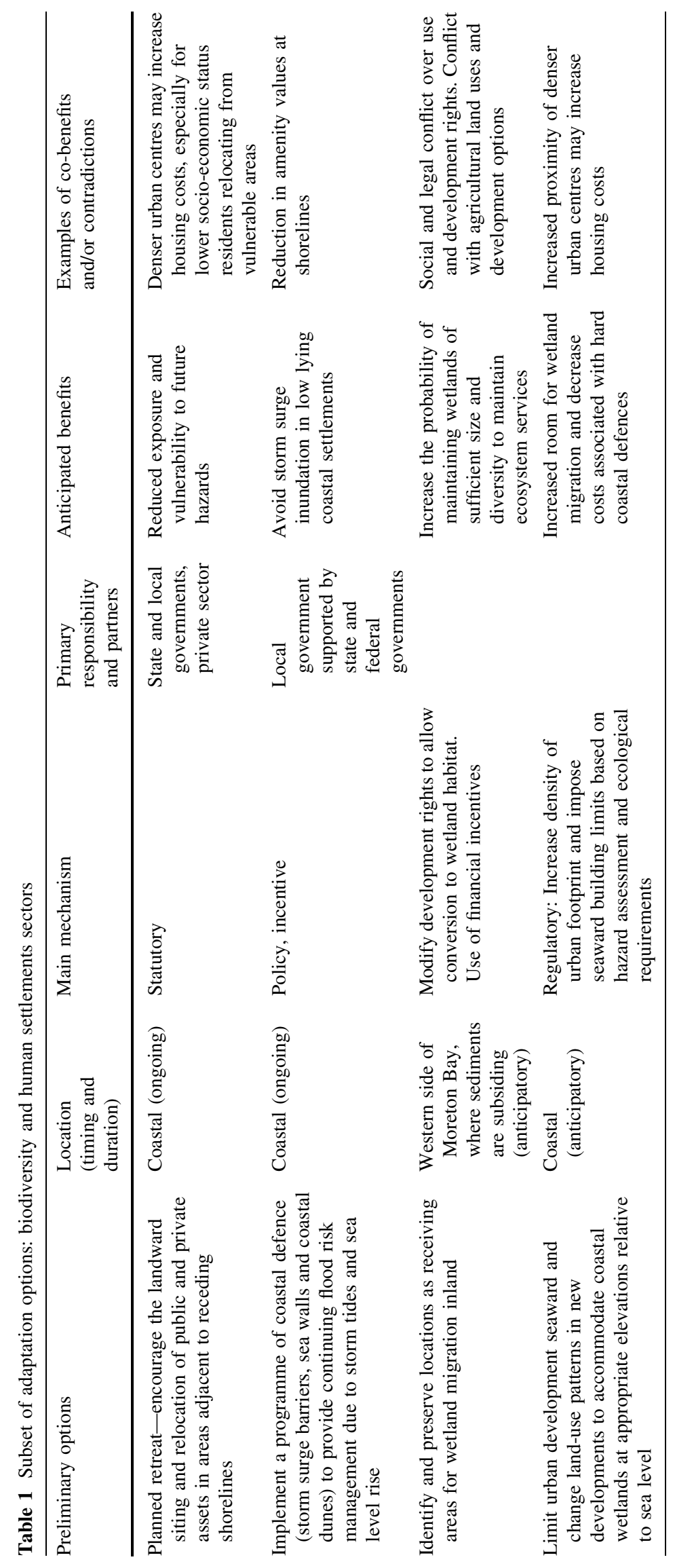




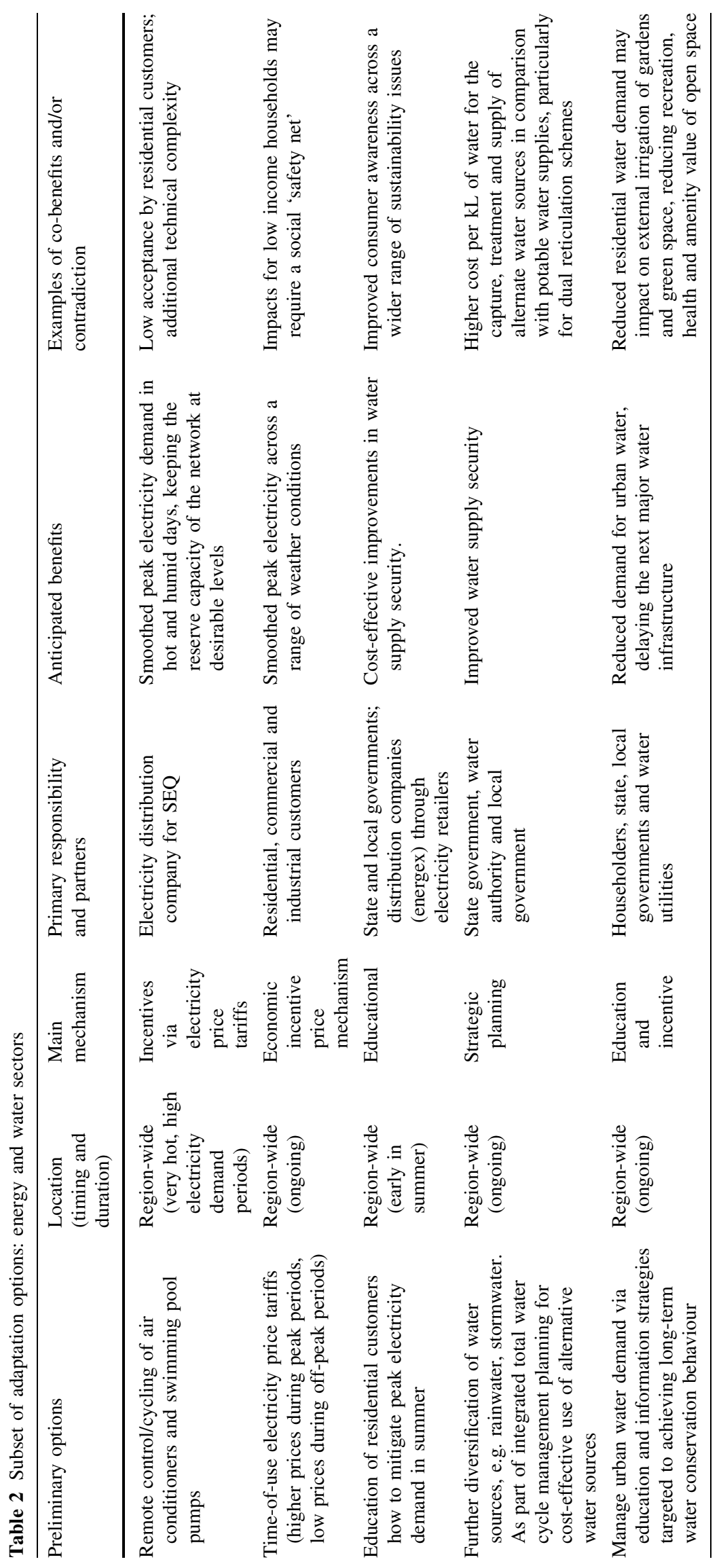




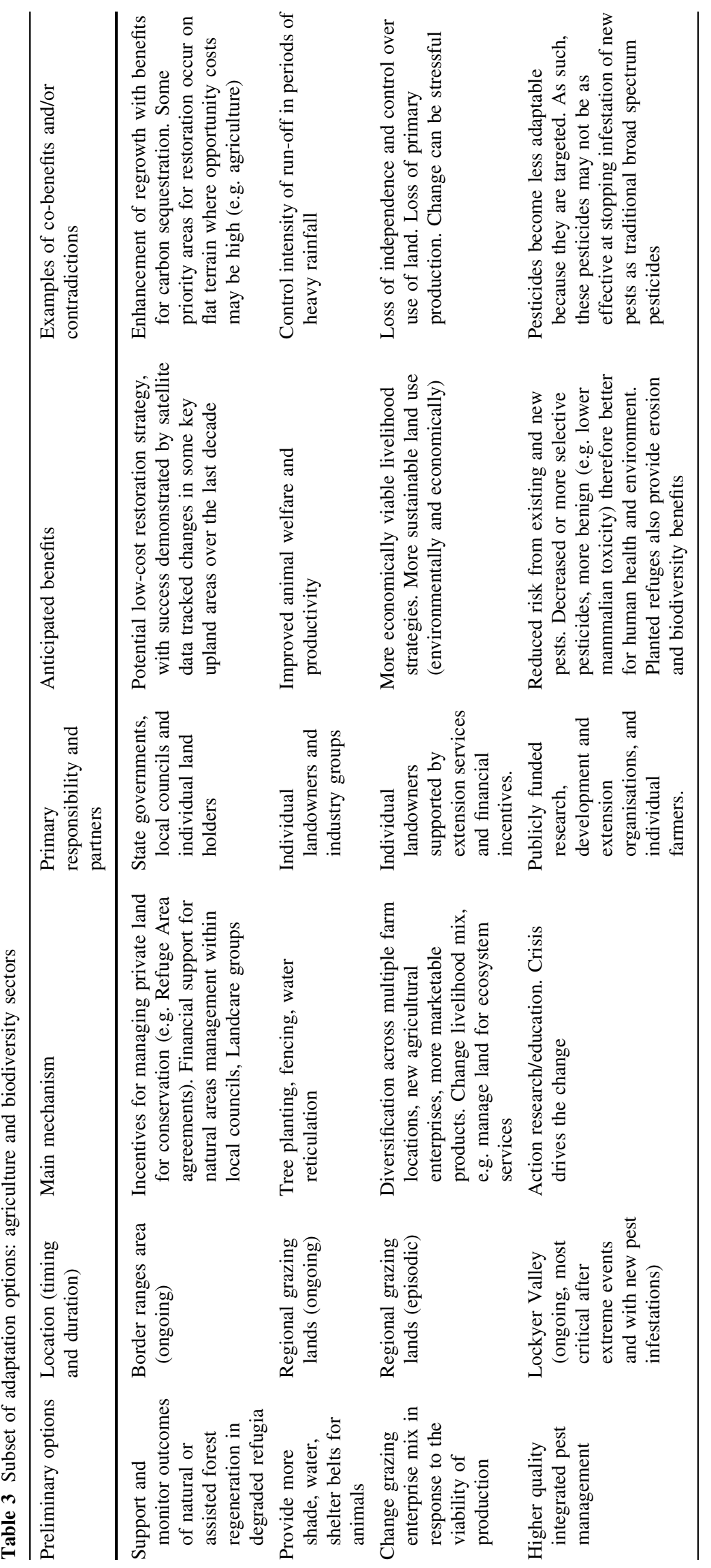


1. actions involved;

2. most suitable or likely policy mechanism of implementation (e.g. regulatory, incentive and informational);

3. proposed scale and/or location of implementation;

4. temporal characteristics of the action (episodic, sequential, ongoing);

5. primary and secondary responsibilities for implementation; and

6. preliminary thoughts on beneficial or negative interactions with other options.

These tabled lists were then circulated amongst all participant researchers to build awareness of likely actions being proposed in other sectors. There were two or three iterations in this process as researchers distilled their understanding of their research implications into more practical and discrete lists of adaptation actions. These preliminary adaptation options served as the content in the first of two face-to-face cross-sectoral discussions in the following step.

\section{Step 2: Exploring co-benefits and contradictions}

A first workshop was organised in November 2011 with researchers from the project, an Australian government observer and the two authors. The purpose of this workshop was to identify subsets of adaptation options (from step one, above) that researchers considered most likely to exhibit interdependencies and provide the opportunity for other researchers to interrogate the scientific and practical claims behind these options. The result of this exchange was a subset of six groups of options identified as exhibiting, prima facie, strongly interdependent traits. Using small-group discussions (working in cross-sectoral, multidisciplinary groups), researchers then explored and documented specific co-benefits and contradictions, followed by validation of these amongst the broader group. Outcomes of the discussions were documented and circulated to participants for considered reflection and further clarification. Importantly, the intent here was not to identify and assess the full suite of potential co-benefits or contradictions but to focus on several examples. These examples, through the process of examination, serve as instructive cases of the types of interactions that might be expected in the region.

\section{Step 3: Considering horizontal and vertical interplay}

Where the first workshop addressed consequences or impacts of interactions between options, the second workshop focused on the processes and scales of interaction. This second synthesis workshop was held with mostly the same group of researchers ${ }^{2}$ in March 2012. The purpose of this second workshop was to extend earlier discussions on likely interactions, but this time using concepts of horizontal and vertical interplay to frame the conversation. This encouraged researchers to consider cross-scalar as well as cross-sectoral interactions. Because of the increasingly sophisticated requirements of the discussion, this second full-day workshop explored only three of the six previously identified adaptation subsets (Tables 1, 2, 3). Again, this occurred through two rounds of directed smallgroup discussion and was followed again by validation with the broader group. In this way, the selection of the three suites of options in the analysis was based on initial expert-based, subjective assessment by researchers. These were then refined and prioritised through the inter-subjective process of dialogue amongst the broader group of researchers.

Step 4: Developing and interpreting the indicative cases

In the final stage, we compiled and consolidated the cases and again sought feedback from participants to refine and validate the authors' interpretations. The three subsets of options that were explored in Step 3, above, served as illustrative and indicative cases into the character of research integration for regional adaptation. The cumulative products from the two workshops, compiled written material and follow-up discussions with researchers, produced a rich body of material on the three indicative cases.

Where other studies have undertaken the analyses of planned or agreed adaptation measures for regions (see Reyer et al. 2012), this study examines options that are still in development. As such, the results below provide an ex ante appraisal. This approach is beneficial in pre-empting likely consequences of interactions, so a more complete understanding of proposed implementation measures can be examined with policy-makers and other stakeholders. One limitation of such an approach is that there is no clear commitment that these will indeed be the final measures adopted for implementation. However, it does provide for a more considered and holistic examination of likely measures and the types of interactions that could be expected.

\section{Results: assessing interactions amongst selected adaptation options}

Below, we present the results of discussions amongst project researchers, focusing on three subsets of adaptation options. For each of these subsets, the co-benefits, contradictions, and vertical and horizontal interactions are

\footnotetext{
${ }^{2}$ Fifteen participants in each of the two workshops with thirteen of these attending both.
} 
described. Importantly, the material in this section is intended to reflect the internal project dialogue on these options. This dialogue is based on participant's research, and reference to their work is provided to evidence the particular cases and options.

Planned retreat, coastal defence and wetland migration

Up to 35,000 SEQ residences are already at some risk of inundation in 100 average recurrence interval storm surge events (Wang et al. 2010). Two adaptive strategies proposed by researchers were to either plan a retreat from locations at risk, or strengthen coastal defences with hard infrastructure (Serrao-Neumann et al. 2013). The choice of adaptation has implications for the region's $\approx 160 \mathrm{~km}^{2}$ of coastal wetlands, which includes wetlands of international ('the Ramsar convention') and national significance. As sea level rises, coastal wetlands have the ability to colonise new areas on progressively higher ground (see Shoo et al. 2012). To support this adaptation, however, the likely paths of advancing wetlands will need to be clear of hard (urban) infrastructure and other obstacles (Traill et al. 2011).

\section{Co-benefits}

Planned retreat removes the human population from vulnerable locations and also provides space for landward migration of wetlands. Amenity benefits may accrue to the remaining residents due to closer proximity to new natural areas. Increased housing density and redevelopment behind retreated areas have the potential to help meet housing affordability and other sustainability goals. Co-benefits can be increased by prioritising retreat in areas with high wetland value potential. Retreat can also provide open space and access in foreshore areas, and redirect costs that would otherwise be used for hardening coastal defences.

\section{Contradictions}

Where hard defensive structures are used, negative interactions with conservation of coastal biodiversity are likely. These include the loss of existing wetlands and reduction in the diversity of wetland habitats in those locations (Shoo et al. 2012). Higher density developments behind the defended areas may have negative implications for equity and access, with remaining residences likely to be more expensive, or conversely less desirable if environmental quality of residential areas deteriorates due to proximity to mosquito habit, for example. Planned retreat may increase development pressure on other coastal forests and wetlands (e.g. melaleuca).

\section{Vertical interactions}

Confusion or conflict over jurisdictional responsibilities, between agencies at different scales, is likely to be exacerbated under conditions of planned retreat. This argument was linked to concerns about consistent policy interpretation across agencies at different levels of government, particularly between local and state (provincial-level) governments on buffer-zone rules. Similarly, local-state cooperation would be necessary when implementing local planning responses that involve changes to land tenure or property rights. This included cooperation on key tasks such as facilitating retreat and planned migration in identified risk areas, and for identifying and allocating land to accommodate that retreat and migration. This is not to mention the likely resistance from property owners in areas that are subject to retreat policies. On this issue, there were suggestions that non-government entities such as regional natural resource management bodies or other regional-level partnerships might provide important connections between state and Australian governments and communities, particularly through educational, informational and monitoring functions that engage through local sites and actors.

The involvement of the Australian (national-level) government in implementing adaptation was also raised. First, it was suggested that local authorities would be dependent on the Australian government for financing land acquisition for retreat in strategic areas or other land purchases required for the accommodation of wetland migration under a managed retreat scenario. Second, major infrastructure improvements to defend property and/or existing use rights were considered beyond the financial means of most local authorities. Third, the national government's protection of regional salt marsh ecosystems brings a federal legislative instrument more firmly into play in local development decisions. It also raises the potential for increased Australian government involvement through the provision of funds for managing these changes.

\section{Horizontal interactions}

Relationships between households in identified risk locations, and the degree to which those households shared common values and expectations at a neighbourhood level, were considered influential in the capacity of local authorities to garner support (or otherwise) for major changes to land use. Similarly, relationships between neighbouring councils in the region (e.g. networks such as 
the South East Queensland Council of Mayors) were seen as critical to enhancing the capacity of local governments to coordinate planning response across jurisdictional boundaries. Failure to do so would obstruct ecosystemlevel management responses along the coast. For example, managing coastal erosion and inundation in locations at the juncture between two local government areas would be problematic if conflicting responses (hard, soft or now, later) were adopted. In the context of these concerns about cooperation between government agencies, arguments were made that a new organisational entity (or authority) with a clear mandate to manage across jurisdictions on the coastline would be necessary.

Water and energy use in households

The so-called Millennium drought reduced SEQ water supplies to critical levels by 2007 and promoted major behavioural, technological, and infrastructure changes (Laves et al. 2013). The drought broke with flooding rains (Bohensky and Leitch 2013), but climate change projections indicate that in the future, dam replenishing streamflows will decrease (Gooda et al. 2011). Urban water supplies need to be secured by diversifying supply away from the current heavy dependence on bulk supplies based on dams (Laves et al. 2013). Researchers at the workshop identified that desalination, recycling wastewater and decentralisation through household water tanks are options currently being deployed in SEQ. This will add to regional energy demands. However, energy utilities and governments are concurrently proposing adaptations to reduce peak energy demand (see Quezada et al. 2013). Unplanned energy failures in heat wave conditions are a major health risk in the region, and peak demand has grown twice as quickly as average energy demand growth in recent years (Seo et al. 2013). Adaptations for managing peak energy demand include encouraging greater energy efficiencies at the household scale.

\section{Co-benefits}

At a regional scale, both sectors' adaptation options independently rely on some level of decentralisation of generation and/or supply infrastructure. Energy utilities in the region are already encouraging changes to the temporal patterns of household energy consumption to reduce peak loads. Water utilities have inadvertently delivered co-benefits by reducing energy usage through past campaigns to reduce water consumption. Conversely, water utilities have also employed more energy intense water source options (desalination, purified recycled drinking water). Some improvement in both energy and water efficiencies can be achieved by improved articulation between these systems at household scales. This could be gained through broadbased conversion to solar hot-water and smart technology to use appliances both outside of peak energy demand periods but also timed to take advantage of the solar hotwater at its maximum production.

\section{Contradictions}

Available options for diversifying water supplies all increase the energy intensity of urban water use. At the household level, rainwater tanks provide perceived benefits in terms of water security during dry periods. Yet, on a cost-per-litre basis, tank water is considerably less economical than standard potable supply (due to tank infrastructure costs and localised pump energy usage). As such, increased energy costs under this scenario contribute to cost-of-living pressures at household scales (potentially increasing socio-economic vulnerability of lower-income households) as well as increasing the vulnerability of regional energy infrastructure as both energy and water demand increases. Diversification of water supply sources, particularly desalinisation, also increases energy demand.

\section{Vertical interplay}

Discussion amongst researchers at the workshops identified interactions between household and higher levels of organisation such as the neighbourhood, regional or national levels. For instance, change at household scale could be encouraged through the tightening of building codes or regulations that require improved integration and greater efficiency in water and energy use. This would require action from local governments in cooperation with state government agencies to amend and upgrade existing design and building standards, particularly for new developments where gains are most readily and cost-effectively made at scale.

The discussion repeatedly turned to issues of how improved integration between local or household-level energy and water use efficiencies might be pursued at neighbourhood level or multi-dwelling clusters. At the heart of these options is the degree to which cost-efficient and maintainable decentralised systems can firstly be designed and operated on a multiple-dwelling basis, and secondly, how these connect to the broader regional resource networks (i.e. the power grid or potable water supply system).

Resolving these existing discontinuities between scales of generation and supply (i.e. between household and grid) will require novel forms of cooperation between utilities, governments and major developers (see Quezada et al. 2013). However, in this regard, current actions by governments or utilities to incentivise energy or water savings 
at household scale are of limited efficacy. Researchers at the workshop therefore felt there was an ongoing, defined role for statutory development authorities to facilitate (or indeed mandate) cooperation amongst developers, governments and utilities to achieve this goal. Such cooperation could be underscored by government-funded incentive schemes to mainstream decentralised energy-water systems into housing and development markets more rapidly in the region.

\section{Horizontal interplay}

Researchers at the workshop commented that there are presently contradictions between state government policies seeking to improve the affordability of housing in the region whilst, at the same time, encouraging greater resource-use efficiency and sustainability in housing design. As such, in the policy discourses on development in the region, there is a perceived conflict between pressures to keep housing costs low, and the contentious claims of developers that meeting sustainability objectives increases those costs (see Taylor et al. 2012, 2013).

To deliver the type of integrated infrastructure described earlier also requires attention to horizontal relationships at several levels. These may include, for example, new types of agreements amongst residents at the cluster or locality scale, and between utilities, developers and planning authorities (e.g. through precinct level, neighbourhood or whole-of-development planning at sub-regional levels). These agreements would need to articulate the rules and practices of ownership, maintenance and management of cluster level infrastructure within neighbourhoods. Ambiguities about infrastructure and service charges for these new models and joint-operating arrangements between stakeholders will need to be resolved.

\section{Terrestrial biodiversity and agricultural viability}

South-East Queensland is one of Australia's five major centres of plant diversity and endemism (see Shoo et al. 2012). To protect regional biodiversity, habitats need protection and restoration in key areas identified as providing a refuge from climate change. Strategic intervention to assist passive regeneration of native forest may be a low-cost option to achieve restoration objectives (see Shoo et al. 2012). However, such activities interact with regional agricultural adaptation. About $56 \%$ of SEQ's woody vegetation has been cleared, with grazing accounting for the dominant land use in rural areas. For SEQ's agricultural industry, responding to increasing climate variability will require improving integrated pest management in cropping lands and providing more shade, water, and shelter belts for grazing animals (Zvi Hochman, Neil Huth, Personal communications.). Both of these sets of options need to be seen in the context of peri-urbanisation pressures and structural adjustment pressures operating at farming enterprise and industry levels (see Harman and Low Choy 2011).

\section{Co-benefits}

Researchers at the workshops discussed how encouraging passive forest regeneration for biodiversity outcomes may provide several benefits for beef cattle producers. Landscape regeneration may serve to moderate exposure to climate extremes and local provision of shade from trees can reduce heat stress on animals. Mitigating the excesses of hotter and drier conditions may lengthen the time frames producers have to adapt their enterprise structure, management practices, varieties or breeds. In turn, this reduces the need for rapid adjustment with its potentially undesirable socio-economic impacts for farming businesses and communities. For horticultural enterprises in particular, passive regeneration could be planned to increase the proximity of pollinators and crop pest predators to cropping areas reducing reliance on chemical inputs, help moderate temperature range extremes and reduce evaporative stress on crops. If situated in important groundwater recharge areas, increased forest cover may reduce the effects of dry-land salinity and lead to improved water quality in catchments. Encouraging passive regeneration may increase rural amenity and provide for income diversification through amenity tourism or carbon sequestrationbased incomes for enterprises under adjustment pressures.

\section{Contradictions}

Conversely, given that the expected annual number of fire danger days will increase under climate change in the region, encouraging passive forest regeneration adjacent to rural (and peri-urban) land may increase exposure to fire risks to human settlements. Decline in the total area of land actively managed under rural production may also increase the risk of weed infestation. Other physical risks noted were increased strain on available groundwater resources if broad-scale forest regeneration increased rates of evaporative transpiration. This could reduce available water for agriculture adding to stress on enterprises. Conflicts may also arise between the maintenance of high-value agricultural land uses and revegetation of regional ecosystems on flatter more fertile lands occupied by agriculture (Shoo et al., in press). Hence, the greatest opportunity for regeneration may be in locations least suited to agriculture, such as the drier, more exposed upland areas of catchments. 
Fig. 1 Interplay between adaptation options in the SouthEast Queensland region: illustrative examples from case studies

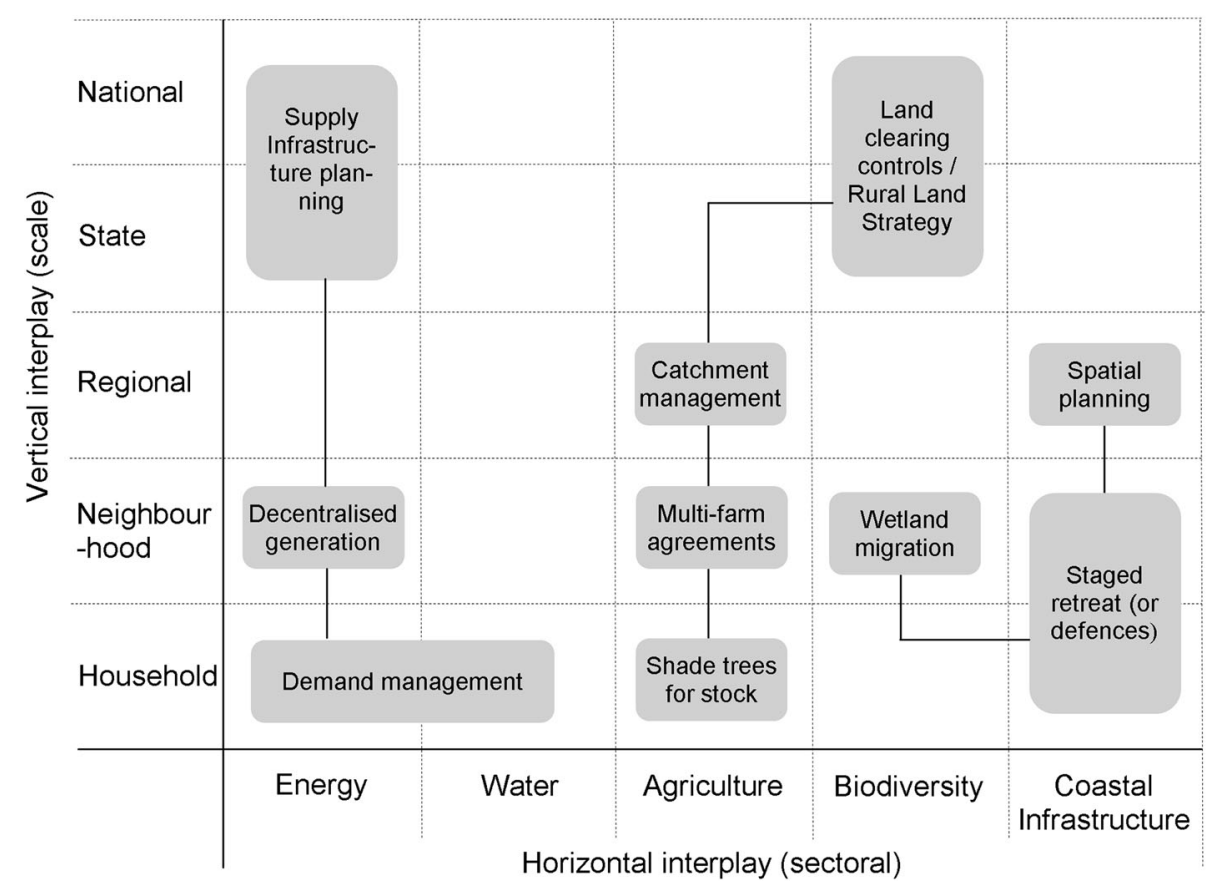

\section{Vertical interplay}

Conservation priorities are tied to parcels of land for their biodiversity values and also to the priorities of managing agencies. Because of this, actions to secure land for conservation may not be well aligned with opportunities to secure land arising from rural-industry restructuring in the region. Similarly, there is a need to match regional or higher-level planning objectives (e.g. to sequester carbon in the landscape) with the potential to manage or regenerate native vegetation at farm scales. Where partnerships between individual farmers and governments can be brokered through incentive payments, for instance, that vertical relationship needs to persist over time. Providing (ongoing) incentives to plant, maintain or regenerate native vegetation were considered necessary to achieve longer-term outcomes by providing a stable and predictable set of benefits to landholders. This can be problematic as rural landholders, particularly those experiencing processes of structural change in their industry, may be reluctant to commit to binding land agreements that suggest some loss of management control over their farm. In SEQ, this reluctance may be more acute given the high proportion of freehold, rather than leasehold, tenure of agricultural production.

\section{Horizontal interplay}

Passive forest regeneration on individual properties will not necessarily be coordinated with neighbours to achieve landscape-wide objectives, such as improving connectivity or mitigating temperature extremes. There are also issues with how co-benefits might be gained 'over-the-fence' when one landholder has limited formal control over their neighbour. For instance, horticultural enterprises located close to stands of native vegetation may have limited influence over neighbouring land from which integrated pest management services are provided. Conversely, there is no similar mechanism to return profits from the agricultural enterprise to that neighbouring land in order to sustain those services. In a similar vein, cooperation amongst neighbouring landholders to maintain the overall productive qualities of an area (e.g. limit hillside erosion across property boundaries) is hampered by incentive structures that tend to direct rehabilitation payments to individual properties that are often the most degraded. These sorts of issues highlight the importance of forming local agreements between neighbours if these co-benefits are to be gained and maintained between agricultural viability and biodiversity adaptations in the region.

\section{Discussion}

We applied a discursive, structured approach to identify and explore principal functional and political interdependencies between adaptation options proposed in different sectors. In describing these interactions in terms of their co-benefits, contradictions, horizontal and vertical interplay, it can be seen how these interactions condition the success-or otherwise-of proposed sectoral options. For example, in functional terms, actions to improve the security and efficiency of water supply to households in the region will have 
direct consequences for household energy consumption. In this way, rules and practices associated with household water use and preferred supply strategies are tied to the viability of future energy regimes. Discussion amongst researchers identified both a spatial and political response to this nexus. The spatial response proposed is to redefine the focal scale of supply and/or generation from individual household to the dwelling-cluster or neighbourhood scale. Neighbourhood-scale water and energy supply strategies are most likely to achieve household-scale benefits, provided they are integrated within the broader regionalnational supply/generation networks. These functional interdependencies, as Young (2002) suggests, also create political ones where improved horizontal cooperation amongst utilities, developers and regional planning authorities will be necessary to implement such a strategy. Even though incentives to manage interactions between water and energy are weak (see Quezada et al. 2013), planning to avoid future joint losses in both sectors may eventually force cooperation (Young 2002).

Interestingly, discussions amongst researchers at the workshops across all three suites of adaptation options presented in this paper suggest a refocus on new, intermediate levels of organisation (as illustrated in Fig. 1). New organisation is required at scales between local government and individual households or businesses. The planned retreat-wetland migration case, for instance, suggests that an adaptation response that differentiates between coastal neighbourhoods will be likely, and necessary, to achieve biodiversity outcomes and the protection of human settlements. Where one locality may be identified for future retreat (and potentially allocated for the landward migration of wetlands as well), an adjacent locality may be defended. This exemplifies the need for detailed local planning, participation and debate with those specific communities to work through what may otherwise be viewed as an inconsistent and complex response of planning authorities to neighbouring coastal settlements (Bai et al. 2010). Similarly, a greater degree of formalised cooperation between adjacent agricultural landholders, and between neighbouring conservation and agricultural lands, will be necessary to ensure passive forest regeneration occurs in a manner that provides benefits for managing climate variability and improved agricultural viability. This will require sub-regional coordination to align spatial priorities for passive regeneration and future agricultural production land, and hence avoids competing regimes. Each of these examples emphasises a degree of horizontal interplay otherwise not articulated in adaptation options as defined in the initial sector-specific focus.

So, how does the synthesis approach used above inform how we think about regional adaptation research and implementation of its recommendations? Our approach embeds a capacity for synthetic thinking into the internal dialogue between researchers. It also intentionally narrows (or focuses) attention from a large number of discrete options to small subsets of options. Importantly, the case descriptions reflect the types of interactions most evident to participant researchers. Stakeholder engagement is important for planning and implementation (e.g. Schmidt et al. 2012), and our project's stakeholder interactions are described elsewhere (Serrao-Neumann et al. 2013; Keys et al. 2013). For the exercise detailed above, we note that similar discussions undertaken with government managers or other stakeholders will have generated a different set of narratives. Nevertheless, our approach encouraged a sifting or informal prioritisation of actions, from a researcher perspective, that were more likely to require considered thinking about integration. Counter to the prevailing paradigm, this was done without deterministic prioritisation processes, but in the course of structured dialogue. The approach employed in this study also mimics the processes of dialogue in multisectoral policy problems where despite the rhetoric of comprehensiveness, integration must for pragmatic reasons focus on discrete and specific subsets of functional or political interactions - some narratives dominate over others. More important to the policy analyst and policy-maker however is not so much what is discussed (as this will be highly contextual) but what those discussions tell us about the rules in use (or proposed rules in use) for guiding a more cohesive regional-level understanding of implications of the research for implementation. What the synthesis process does is to emphasise the task of integration in complex environmental research and policy problems. Further, such an approach is defensible as it provides an analytically robust way to lead participants to an improved understanding of the problems, and the opportunities, at hand.

\section{Conclusion}

This paper illustrates a process of research synthesis applied in a large, regional-scale climate adaptation project. A series of structured discussions amongst project researchers was conducted to identify and describe interactions between suites of sector-specific adaptation options developed for the region. This facilitated a more integrated understanding of options being proposed by specific sectoral domains. It also pointed to important, emergent properties of implementation that cut across discrete sectoral options, such as the importance of neighbourhood and local level planning responses as focal sites of integrated implementation. Further, it highlights how recognising interactions between scales of institutional organisationsuch as state, region and locality-is critical for designing complex regional adaptation programmes. 
There is a very practical objective in conducting a synthesis process-to provide the means through which researchers as an expert group in adaptation policy-making can examine likely co-benefits and contradictions otherwise not articulated within their distinct research domains. In doing so, we demonstrate the value of an institutional perspective for unpacking regional integration, a perspective that is sensitive to research synthesis and policy implementation in climate adaptation more broadly.

Acknowledgments Our thanks to the SEQCARI project researchers for their contributions to this synthesis process and to Don Begbie, South-East Queensland Urban Water Security Research Alliance who contributed to discussions on water sector issues. Tim Smith, Tom Measham and Nadine Marshall provided helpful comments on earlier versions of this paper as did the two anonymous reviewers and the editor. This paper is part of the SEQCARI, a partnership between the Queensland and Australian Governments, the CSIRO Climate Adaptation National Research Flagship, Griffith University, University of the Sunshine Coast, and, University of Queensland.

Open Access This article is distributed under the terms of the Creative Commons Attribution License which permits any use, distribution, and reproduction in any medium, provided the original author(s) and the source are credited.

\section{References}

Agrawal A (2008) The role of local institutions in adaptation to climate change. Social Development Department, The World Bank, Washington, DC

Agrawal A, Lemos MC, Orlove B, Ribot J (2012) Cool heads for a hot world-social sciences under a changing sky. Glob Environ Chang 22:329-331. doi:10.1016/j.gloenvcha.2012.02.003

Bai X, McAllister RRJ, Beaty M, Taylor B (2010) Urban policy and governance in a global environment: complex system, scale mismatch and public participation. Curr Opin Environ Sustain 2:129-135. doi:10.1016/j.cosust.2010.05.008

Biswas AK, Tortajada C (2010) Future water governance: problems and perspectives. Int J Water Resour D 26:129-139. doi:10. 1080/07900627.2010.488853

Bohensky E, Leitch A (2013) Framing the flood: a media analysis of themes of resilience in the 2011 Brisbane flood. Reg Environ Chang. doi:10.1007/s10113-013-0438-2

Bulkeley H (2010) Cities and the governing of climate change. Annu Rev Environ Resour 35:229-253. doi:10.1146/annurev-environ072809-101747

Derkzen P, Bock BB, Wiskerke JSC (2009) Integrated rural policy in context: a case study on the meaning of "integration" and the politics of "sectoring". J Environ Policy Plan 11:143-163. doi:10.1080/15239080902920126

Fischer F (2003) Reframing public policy: discursive politics and deliberative practices. Oxford University Press, Oxford

Forester J (1989) Planning in the face of power. University of California Press, Berkeley

Gooda MC,Voogt S, Vitkovsky JP (2011) Climate change impact on water availability in the South East Queensland region. In: Begbie DK, Wakem SL (eds) Science forum and stakeholder engagement: building linkages, collaboration and science quality, Urban Water Security Alliance, Brisbane, 14-15 September
Gunningham N, Rees J (1997) Industry self regulation: an institutional perspective. Law Policy 19(4):363-414

Hajer MA, Wagenaar H (eds) (2003) Deliberative policy analysis: understanding governance in the network society. Cambridge University Press, Cambridge

Hanger S, Pfenninger S, Dreyfus M, Patt A (2013) Knowledge and information needs of adaptation policy-makers: a European study. Reg Environ Chang 13:91-101. doi:10.1007/s10113-012-0317-2

Harman B, Low Choy D (2011) Perspectives on tradeable development rights for ecosystem service protection. J Environ Plan Manag 54:617-635. doi:10.1080/09640568.2010.526405

Hill MJ, Olson R (2013) Possible future trade-offs between agriculture, energy production, and biodiversity conservation in North Dakota. Reg Environ Chang 13:311-328. doi:10.1007/s10113012-0339-9

Holman IP, Nicholls RJ, Berry PM, Harrison PA, Audsley E, Shackley S, Rounsevell MDA (2005) A regional, multi-sectoral and integrated assessment of the impacts of climate and socioeconomic change in the UK. Clim Chang 71:43-73. doi:10.1007/ s10584-005-5956-6

Hunt A, Watkiss P (2011) Climate change impacts and adaptation in cities: a review of the literature. Clim Chang 104:13-49. doi:10. 1007/s10584-010-9975-6

Keys N, Bussey M, Thomsen DC, Lynam T, Smith TF (2013) Building adaptive capacity in south east Queensland, Australia. Reg Environ Chang. doi:10.1007/s10113-012-0394-2

Kirshen P, Ruth M, Anderson W (2008) Interdependencies of urban climate change impacts and adaptation strategies: a case study of Metropolitan Boston USA. Clim Chang 86:105-122. doi:10. 1007/s10584-007-9252-5

Lane MB, Robinson C, Taylor B (2009) Contested country: local and regional natural resource management in Australia. CSIRO, Collingwood

Laves G, Kenway S, Begbie D, Roiko, A (2013) Still waters running deep: building adaptive capacity in the South East Queensland water supply sector through research. Unpublished report. Reg Environ Chang (under preparation)

Leitch A, Harman B, Lane MB (2010) From blueprint to footprint: climate change and the challenge for planning. In: Bonyhady $\mathrm{T}$, Macintosh A, McDonald J (eds) Adaptation to climate change: law and policy. The Federation Press, Sydney

Lovell H, Bulkeley H, Owens S (2009) Converging agendas? Energy and climate change policies in the UK. Environ Plan C 27:90-109. doi:10.1068/c0797j

Low N (2008) In praise of public planning in an era of climate change. Urban Policy Res 26:141-144. doi:10.1080/0811114080 2054299

Mather A, Roberts D, Tooley G (2011) Adaptation in practice: Durban, South Africa. In: Otto-Zimmermann K (ed) Resilient cities. Springer, Netherlands, pp 543-563

McAllister RRJ, McCrea R, Lubell M (2013) Policy networks, stakeholder interactions and climate adaptation in the region of South East Queensland, Australia. Reg Environ Chang. doi:10. 1007/s10113-013-0489-4

Mitchell B (1990) Integrated water management: international experiences and perspectives. Belhaven, London

Moffet V, Alibert M, Larrivée C (2011) Interdisciplinary and multiinstitutional approaches to climate change adaptation. In: Zimmermann M, Otto-Zimmermann K (eds) Resilient cities. Springer, Netherlands, pp 213-221

Morrison TH (2007) Multiscalar governance and regional environmental management in Australia. Space Policy 11:227-241. doi:10.1080/13562570701811551

Owens S, Rayner T (1999) When knowledge matters: the role and influence of the royal commission on environmental pollution. J Environ Policy Plan 1:7-24 
Ozawa C (2005) Putting science in its place. In: Scholz JT, Stiftel B (eds) Adaptive governance and water conflict: new institutions for collaborative planning. Resources for the Future Press, Washington, DC, pp 185-195

Quezada G, Grozev G, Seo S, Wang C-h (2013) The challenge of adapting centralised electricity systems: peak demand and maladaptation in South East Queensland, Australia. Reg Environ Chang. doi:10.1007/s10113-013-0480-0

Rambaldi AN, Fletcher CS, Collins K, McAllister RRJ (2013) Housing shadow prices in an inundation prone suburb. Urban Stud 50:1889-1905. doi:10.1177/0042098012465904

Reyer C, Bachinger J, Bloch R, Hattermann F, Ibisch P, Kreft S, Lasch P, Lucht W, Nowicki C, Spathelf P, Stock M, Welp M (2012) Climate change adaptation and sustainable regional development: a case study for the Federal State of Brandenburg, Germany. Reg Environ Chang 12:523-542. doi:10.1007/s10113011-0269-y

Rydin Y (2003) Conflict, consensus and rationality in environmental planning: an institutional discourse approach. Oxford University Press, Oxford

Schmidt A, Striegnitz M, Kuhn K (2012) Integrating regional perceptions into climate change adaptation: a transdisciplinary case study from Germany's North Sea Coast. Reg Environ Chang. doi:10.1007/s10113-012-0338-x

Scholz JT, Stiftel B (2005) Adaptive governance and water conflict: New institutions for collaborative planning. Resources for the Future, Washington, DC

Seo S, C-h Wang, Grozev G (2013) Cooling energy consumption and reduction effect for residential buildings in South East Queensland, Australia. Built Environ 59:408-416. doi:10.1016/j. buildenv.2012.09.006

Serrao-Neumann S, Crick F, Harman B, Sano M, Sahin O, van Staden R, Schuch G, Baum S, Low Choy D (2013) Improving crosssectoral climate change adaptation for coastal settlements: insights from South East Queensland, Australia. Reg Environ Chang. doi:10.1007/s10113-013-0442-6

Shoo LP, O’Mara J, Parhans K, Rhodes JR, Runting R, Schmidt S, Traill LW, Weber L, Wilson K, Lovelock CE (2012) Moving beyond the conceptual: specificity in regional climate change adaptation actions for biodiversity in South East Queensland, Australia. Reg Environ Chang. doi:10.1007/s10113-012-0385-3

Shoo LP, Scarth P, Schmidt S, Wilson KA (in press) Reclaiming degraded rainforest: what can we expect? Restor Ecol. doi:10. 1111/j.1526-100X.2012.00916.X

Stewart MG, Wang X (2011) Risk assessment of climate adaptation strategies for extreme wind events in Queensland. CSIRO, Canberra

Taylor BM, Harman B, Heyenga S, McAllister RRJ (2012) Property developers and urban adaptation: conceptual and empirical perspectives on governance. Urban Policy Res 30:5-24. doi:10. 1080/08111146.2011.639178

Taylor BM, Wallington T, Heyenga S, Harman B (2013) Urban growth and climate adaptation in Australia: divergent discourses and implications for governance. Urban Stud. doi:10.1177/ 0042098013484529

Traill LW, Perhans K, Lovelock CE, Prohaska A, McFallan S, Rhodes JR, Wilson KA (2011) Managing for global change: wetland transitions under sea level rise and outcomes for threatened species. Divers Distrib 17:1-9. doi:10.1111/j.14724642.2011.00807.x

Urwin K, Jordan A (2008) Does public policy support or undermine climate change adaptation? Exploring policy interplay across different scales of governance. Glob Environ Chang 18:180-191. doi:10.1016/j.gloenvcha.2007.008.02

van Buuren A, Driessen P, Teisman G, van Rijswick M (2013) Toward legitimate governance strategies for climate adaptation in the Netherlands: combining insights from a legal, planning, and network perspective. Reg Environ Chang. doi:10.1007/ s10113-013-0448-0

Wang X, Stafford Smith DM, McAllister RRJ, Leitch A, McFallan S, Meharg S (2010) Coastal inundation under climate change: a case study in South East Queensland. Climate Adaptation Flagship Working Paper, CSIRO, Brisbane

Young OR (2002) The institutional dimensions of environmental change. MIT, Cambridge

Young OR, Agrawal A, King LA, Sand PH, Underdal A, Wasson M, (1999) Institutional dimensions of global environmental change IHDP report no. 9. IHDP, Bonn 